\title{
The names don't matter but the numbers do: searching for stability in Carboniferous brachiopod paleocommunities from the North American Midcontinent
}

\author{
Luke C. Strotz (1D) and Bruce S. Lieberman (1D
}

\begin{abstract}
A key question in paleoecology and macroevolution is whether assemblages of species (paleocommunities) are persistent entities that endure over millions of years. While community turnover in the face of abiotic change is the presumed norm, paleocommunities have been shown to persist for long time periods and regardless of environmental disruption. It remains an open question, however, as to what processes allow for this. We investigate these questions by analyzing the Carboniferous brachiopod paleocommunities from the Midcontinent of North America. These diverse communities were subjected to repeated and geologically rapid changes in sea level. Using a suite of statistical techniques, we characterize the nature and scope of changes in these paleocommunities over time. We find that, at the paleocommunity scale, there is no evidence for obdurate ecological stasis, with fluctuations in both taxonomic composition and the associated abundance of taxa. However, at a higher ecological scale, stability is manifest, as diversity patterns remain stable across time, with a consistent number of species that can exist in any given paleocommunity. This suggests ecological rules such as taxon packing are in effect, resulting in a form of ecological stability even in the face of constant disequilibrium, and parallels ecological patterns of disruption and recovery previously observed for invertebrate communities from modern marine systems. Based on these results, we advocate for consideration of different hierarchical entities and scales when interpreting the ecological dynamics of fossil assemblages, as focusing exclusively on changes in taxon identity/abundance or diversity levels can lead to very different results.
\end{abstract}

Luke C. Strotz. State Key Laboratory of Continental Dynamics, Shaanxi Key Laboratory of Early Life $\mathcal{E}$ Environments and Department of Geology, Northwest University, Xi'an, 710069, China. E-mail: lukestrotz@ nwu.edu.cn

Bruce S. Lieberman. Biodiversity Institute and Department of Ecology E Evolutionary Biology, University of Kansas, Lawrence, Kansas 66045, U.S.A. E-mail: blieber@ku.edu

Data available from the Dryad Digital Repository: https://doi.org/10.5061/dryad.9p8cz8wf3

\section{Introduction}

Patterns of stability and change in community structure through time, and the processes that drive such patterns, represent an area of significant interest in the fields of ecology and macroevolution (e.g., Paine 1969; Connell and Slatyer 1977; Vrba 1985, 1992, 1993; Eldredge 2001; Mougi and Kondoh 2012). It is generally presumed that abrupt and significant ecological change ultimately leads to cascading extinction with subsequent community collapse. Yet the fossil record has repeatedly demonstrated that, despite changes in the environment, the composition of paleocommunities (sensu Bennington and Bambach 1996) can remain remarkably stable over periods that stretch from thousands to millions of years (Grabau 1898; Cleland 1903; Vrba 1992; Brett and Baird 1995; Morris et al. 1995). The key question is: to what degree are these paleocommunities truly stable, as opposed to just generally similar? (Bennington and Bambach 1996; Brett et al. 1996; Holterhoff 1996; Ivany 1996; Jablonski and Sepkoski 1996; Lieberman and Kloc 1997; Miller 1997; Patzkowsky and Holland 1997; Olszewski and Patzkowsky 2001a,b; Bonuso et al. 2002a,b; Pandolfi 2002; Bonelli et al. 2006; Ivany et al. 2009; Balseiro 2016; Antell et al. 2020). An 
obvious follow-up question also presents itself: if communities are stable, what factors allow them to remain so despite changes in environmental conditions?

The considerable attention paid to the question of community stability and its possible drivers may be due to the broader implications of the results. For example, whether changes in the structure of communities do or do not track shifts in the environment directly bears on understanding the role incumbency plays in mediating community structure (Reymond et al. 2011; Roopnarine et al. 2019), how competition and biotic interactions may influence community composition (Hairston et al. 1960; Tilman 1982; Gallien 2017), and whether the origination and extinction of species is largely driven by ecosystem change (Rundell and Price 2009; Condamine et al. 2013). The last possibility has led to the development of concepts such as "turnover pulse" (Vrba 1985, 1992, 1993) and the "sloshing bucket" (Eldredge 2001) in an attempt to characterize and explain the evolutionary implications of long-term community stability.

The potential archetype of stable paleocommunities is the marine invertebrate fauna from the Middle Devonian Hamilton group of New York State (Brett and Baird 1995). This fauna serves as the type example of the phenomenon known as "coordinated stasis" (Brett and Baird 1995; Morris et al. 1995). Coordinated stasis posits that, at the scale of regional biotas, persistent paleocommunity composition is the default, until it is ultimately interrupted by an associated rapid turnover event involving extinction of preexisting species, the migration or evolution of new species, and the reconstitution of a new functionally and taxonomically distinct paleocommunity. However, whether coordinated stasis holds for the Middle Devonian of New York State, or in other regions and time periods, has been much debated (Brett and Baird 1995; Morris et al. 1995; Bennington and Bambach 1996; Brett et al. 1996; Holterhoff 1996; Ivany 1996; Jablonski and Sepkoski 1996; Lieberman and Kloc 1997; Miller 1997; Patzkowsky and Holland 1997; Olszewski and Patzkowsky 2001a, b; Bonuso et al. 2002a,b; Pandolfi 2002; Bonelli et al. 2006; Ivany et al. 2009; Balseiro 2016; Antell et al. 2020).
To consider these topics further, we use as our touchstone the detailed fossil record of Carboniferous (Pennsylvanian) brachiopod assemblages from the Midcontinent of North America. These were highly diverse assemblages that persisted in an exceptionally dynamic environmental setting. In particular, these paleocommunities were subjected to frequent and geologically rapid phases of marine transgression and regression associated with climate change over approximately a $20 \mathrm{Myr}$ period. Based upon studies of extant communities, theory would predict that this level of disruption should lead to repeated community collapse and associated instability (Bell and Collins 2008; Jackson and Sax 2010). Previous work (Holterhoff 1996; Olszewski and Patzkowsky 2001a), however, has identified the possibility of coordinated stasis in the invertebrate paleocommunities from this frequently perturbed setting, intimating a far more complex ecological scenario is at play. We herein employ a suite of statistical approaches to test whether brachiopod paleocommunities within this regional biota are stable despite the recurring shifts in environmental setting. The possibility of stability is considered by time and environment at multiple hierarchical scales and using different analytical approaches and methods. Results highlight that demonstrating community stability is a fraught process, where the choice of scale and what is being measured can patently affect one's ability to reconstruct patterns of community structure over time.

\section{Materials and Methods}

Environmental Setting.- The specimens used in this study come from the Midcontinent Basin of North America, a sedimentary basin distributed across the U.S. states of Kansas, Nebraska, southwestern Iowa, northwestern Missouri, northern and central Oklahoma, and parts of Arkansas and eastern Colorado (Heckel 2013; Fig. 1). During the Middle to Late Pennsylvanian, this basin formed part of what was an epeiric sea that opened westward into the Proto-Pacific Ocean and, at highstand, covered much of northwestern Laurentia (Heckel 2013). One of the characteristic sedimentary features 


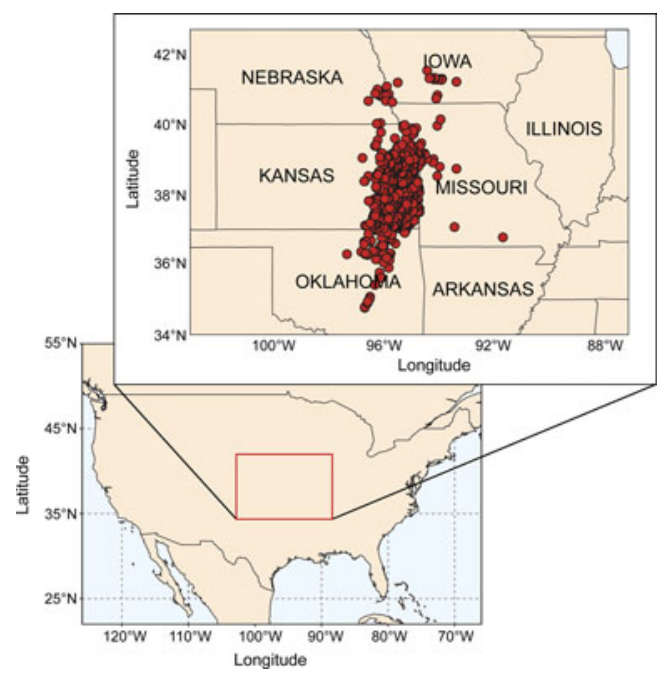

FIGURE 1. Location of sample sites. Map on lower left indicates Midcontinent region of North America that is the focus of our study (marked with box). Map on upper right shows in detail the area that is the source of our samples (including U.S. state boundaries). Dots on upper right map represent individual sample sites.

of the Midcontinent Basin is the presence of repeated cyclothems: successions of marine sediments separated into discrete cycles by intermittent terrestrial strata (Olszewski and Patzkowsky 2001b, 2003). These sequences, beginning in the Desmoinesian and continuing up until the Carboniferous/Permian boundary (Heckel 2013), represent repeating, geologically rapid phases of marine transgression and regression coincident with the waxing and waning of Gondwanan glaciation (Heckel 1986; Heckel 1994). The scale of each transgressive/regressive event varies from major events resulting in basin-wide bathymetric changes to minor bathymetric reversals with limited impact (Felton and Heckel 1996; Heckel 2008).

This relatively exceptional set of conditions provides an ideal setting to test for the presence or absence of community stability in a dynamic environmental setting (Holterhoff 1996; Olszewski and Patzkowsky 2001a). Importantly, the duration of each cycle (approximately 400 kyr) is far less than the duration of the species that inhabited the basin (Holterhoff 1996), thus ensuring the metacommunity present was subject to repeated disruptions. While assessing paleocommunity structure at the level of stratigraphic beds at individual sites, or as close as possible to such a resolution, would be ideal, the limitations of our data make this impractical. Based upon the available data and given the limits of stratigraphic correlation across broad spatial regions, it was necessary to focus our study at the formation level. The formations considered from this particular region and time period do represent a constrained temporal unit for our study, given that individual taxa persist across multiple formations. Further, formations are lithostratigraphic units characterized by a predominant facies type and form only one part of a single major cyclothem, with cyclothems representing allostratigraphic units identified on the basis of their bounding discontinuities (Heckel 2013). This makes it possible for each formation to be assigned to a distinct environmental category based upon the predominant facies present in that formation (Heckel 2013; Fig. 2). It is also true, however, that numerous smaller-scale environmental transitions are occurring within the boundaries of any given formation that we have considered. Moreover, there are even hard to identify paraconformities within any formation for which environmental and paleoecological information is lacking. Thus, the results considered herein should only be treated as applying to and being commensurate with patterns examined at comparable temporal and spatial scales.

We use three environmental categories that parallel those previously proposed by Heckel $(2008,2013)$ as part of his comprehensive paleoenvironmental study of this region. These are:

1. Sea-level highstand phases (HP) — characterized by condonot-rich black and gray phosphatic shales. These represent the peak of a marine transgression.

2. Transitory phases (TP) - characterized by limestone-dominated units deposited during the intermittent stages represented by either Heckel's $(2008,2013)$ transgressive or regressive phases.

3. Sea-level lowstand phases (LP) - characterized by nearshore marine or terrestrial clastic sediments indicative of deltaic systems. These represent the peak of a marine regression. 

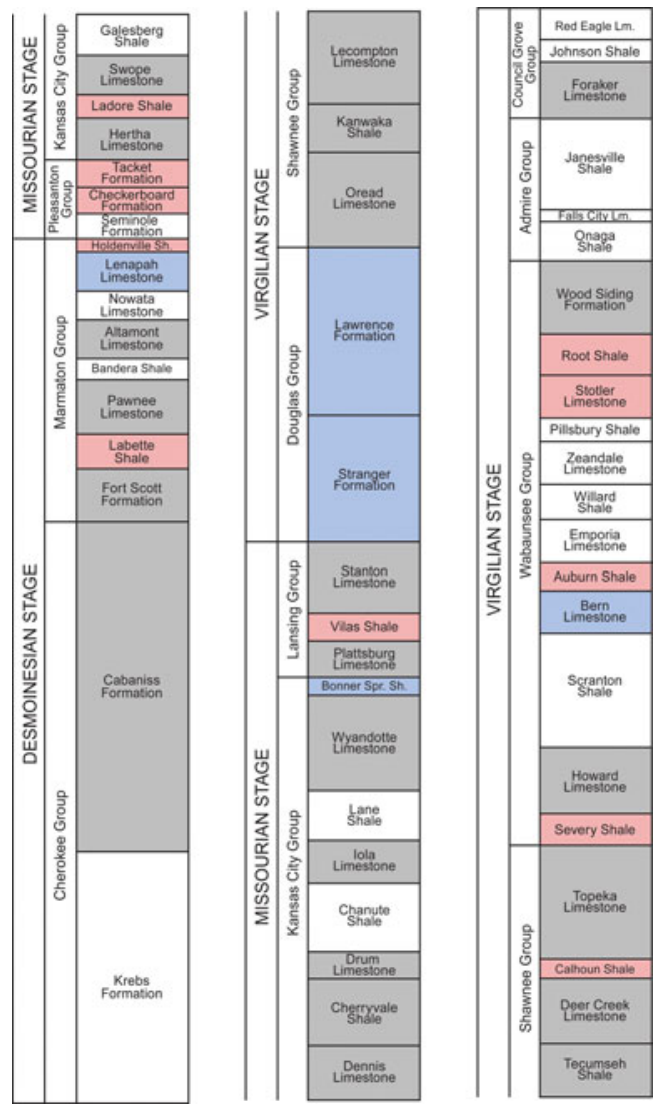

FIGURE 2. Middle and late Pennsylvanian (Desmoinesian to Virgilian) stratigraphy of the Midcontinent of the United States. Stratigraphic chart reads left to right, with the oldest formation on the bottom left and youngest formation on the top right. Colors indicate which environmental category each formation belongs to, as per Heckel (2008, 2013). Red, sea-level lowstand phases (LP); blue, transitory phases (TP); and gray, sea-level highstand phases (HP). Formations in white are those where no or few brachiopods have been collected, usually because these formations are dominated by either marginal marine or terrestrial facies (Heckel 2008, 2013).

It should be noted that these categories do not represent a single static environment, nor are they directly equivalent to a single ecological niche. Rather, they represent a broad set of environmental conditions that are strongly focused around changes in sea level. Sequence boundaries exist between LP and TP that are congruous with the temporal scale that is the focus of our study. Paleocommunities (constructed using the methods described in "Brachiopod Material"), were each assigned to one of these three categories, based upon their stratigraphic position and the paleoenvironmental interpretations of Heckel (2008, 2013), to enable comparisons within and between environmental types.

Brachiopod Material. - Our dataset consists of approximately 43,500 specimens of Pennsylvanian (Desmoinesian to Virgilian) articulated brachiopods from more than 1000 sample sites that today form a rough southwest/northeast transect across the Midcontinent Basin (Fig. 1, Supplementary Table 1). Specimen occurrences were sourced from the collections housed in the University of Kansas Biodiversity Institute, Division of Invertebrate Paleontology collections (KUMIP). Brachiopods were chosen for our study because they represent the dominant functional group in the Midcontinent Basin of North America and would have played a key role in nutrient cycling throughout the basin, both as suspension feeders removing particles from the water column and as a food source for durophagous predators.

As a significant proportion of the Pennsylvanian brachiopod specimens contained within the KUMIP collection have not yet been assigned to species, our study focuses on the generic diversity found within each paleocommunity. Brachiopods are an inherently ecologically conservative group (Rudwick 1970), and thus little information is lost when utilizing brachiopod genera versus species. Numerous studies have previously demonstrated that generic diversity is adequate to assess ecological and paleoecological questions, particularly at the macroscale (e.g., Balmford et al. 2000; Grelle 2002; Villasenor et al. 2005; Clapham and Bottjer 2007).

Only specimens from sample sites that could be definitively assigned to a specific stratigraphic formation of relevant age were included in our analyses. Specimen occurrences were grouped by formation to create paleocommunities, with only paleocommunities of $>50$ specimens retained for analysis. Taxon occurrences and relative abundances for all formations are presented in Supplementary Table 2. The final dataset generated based upon these constraints consists of 38 discrete brachiopod paleocommunities that each represents a single temporal assemblage within the larger basinwide fauna. Given the size and distribution of 
this dataset (both geographic and temporal), when compared with previous analyses of Paleozoic brachiopod paleoecology, it equals or exceeds in size and scale what has been previously used to consider patterns within paleocommunities, both in terms of richness and abundance.

\section{Analyses}

Methodological Framework.-Comparison of community composition and/or diversity between samples lies at the core of the fields of ecology and conservation biology (Magurran and McGill 2011). As such, numerous methods and metrics exist to establish similarity or difference between samples (Santini et al. 2017). Our approach to identifying community stability is based on determining whether the differences in diversity and composition among brachiopod paleocommunities could arise from equivalent assemblages being constituted from the same underlying sampling distribution. If so, any heterogeneities in diversity and taxonomic composition observed among paleocommunities would be no greater than expected from random sampling of a single assemblage. The general model to represent this would be:

$$
\begin{aligned}
\text { Model 1 } & =\left[\mathrm{LP}_{1}=\mathrm{LP}_{2}=\ldots \mathrm{LP}_{i}=\mathrm{TP}_{1}=\mathrm{TP}_{2}\right. \\
& \left.=\ldots \mathrm{TP}_{i}=\mathrm{HP}_{1}=\mathrm{HP}_{2}=\ldots \mathrm{HP}_{i}\right]
\end{aligned}
$$

where LP, TP, and HP correspond to the aforementioned environmental categories derived from the work of Heckel (2008, 2013); the subscripts represent each paleocommunity; and increasing subscript values signify a decrease in paleocommunity age. If this model were corroborated, it would indicate no discernible statistical differences between any of the brachiopod paleocommunities. This would represent a profound form of coordinated stasis in which, regardless of bathymetric or environmental changes, the brachiopod fauna remained essentially unchanged.

If this model is not supported, we consider two alternate possibilities. First, it is possible that stability prevails within each environmental category but not across different environments. In this case, heterogeneity of paleocommunities from each environmental category would be no greater than would be expected from randomly sampling a single paleocommunity from that respective environment. However, heterogeneity between paleocommunities from different environmental categories would be statistically significant. The general model to represent this would be:

Model $2=\left[\mathrm{LP}_{1}=\mathrm{LP}_{2}=\ldots \mathrm{LP}_{i}\right]\left[\mathrm{TP}_{1}=\mathrm{TP}_{2}\right.$

$$
\left.=\ldots \mathrm{TP}_{i}\right]\left[\mathrm{HP}_{1}=\mathrm{HP}_{2}=\ldots \mathrm{HP}_{i}\right]
$$

This represents a more moderate form of paleocommunity stability, in which all paleocommunities that inhabit the same paleoenvironment can be considered to be homogeneous, perhaps as a result of some form of habitat filtering (Baldeck et al. 2013).

Finally, it is possible that no paleocommunity stability is manifest at all and that all paleocommunities are distinct from one another. The general model to represent this would be:

$$
\begin{aligned}
\text { Model 3 }= & {\left[\mathrm{LP}_{1}\right]\left[\mathrm{LP}_{2}\right] \ldots\left[\mathrm{LP}_{i}\right]\left[\mathrm{TP}_{1}\right]\left[\mathrm{TP}_{2}\right] \ldots } \\
& {\left[\mathrm{TP}_{i}\right]\left[\mathrm{HP}_{1}\right]\left[\mathrm{HP}_{2}\right] \ldots\left[\mathrm{HP}_{i}\right] }
\end{aligned}
$$

This might arise because transgressive/regressive events associated with each cyclothem were disruptive enough to obliterate existing brachiopod paleocommunities and ensure that paleocommunities bore no resemblance to either the paleocommunity that had just been wiped out or to any other paleocommunity, previous or subsequent. Further, in this situation, it is likely that environmental forcing would be weak and historical paleocommunity composition would be extraneous, as each paleocommunity is formed anew after each environmental shift.

It would have, of course, been possible to consider many different scenarios beyond these three. With 38 different paleocommunities in our dataset, there are an astronomical number of possible models. Utilizing the vast majority of these models, however, would be capricious, as they clearly have no direct connection to established paleoecological theory. For example, it would be meaningless to assess whether every second LP paleocommunity 
most closely resembled every second HP paleocommunity, or whether paleocommunities that are assigned a prime number are homogeneous. Considering this vast universe of such potential models would also run counter to the goals of our study by obfuscating any potential connections that might exist between specific patterns in the structure of Pennsylvanian brachiopod paleocommunities and the range of ecological processes that we consider herein. The three models we have chosen to focus on represent scenarios that are both ecologically plausible and theoretically consistent and that also align with the approach employed in previous studies exploring the possibility of community stability.

We consider the probability of each of these scenarios using a combination of both multivariate statistics and likelihood-based model ranking methods. Employing multiple approaches allows us to best consider the different ways in which stability might be manifested and because it has been shown that patterns of relative stability or stasis can be obscured by sample size and choice of analytical method (Ivany et al. 2009).

Previous work to identify paleocommunity stability has generally focused on demonstrating either taxonomic stasis, wherein the majority of taxa persist over a protracted temporal interval, or ecological stasis, wherein taxonomic abundances and proportional representation of taxa remains unchanged (Ivany et al. 2009; Nagel-Myers et al. 2013). The primary difference between these two concepts is that the latter includes both taxonomic information and abundance data. We explore the possibility of both taxonomic stasis and ecological stasis using presence data and taxon abundance data, respectively. Additionally, to determine whether community stability is manifest irrespective of taxonomic turnover, we also investigate for potential stability in community biodiversity (Chao et al. 2014).

It should be noted that it is conceivable that there are unspecified differences in preservation potential either of taxa and/or their abundances within each environmental category that could influence our attempt to consider patterns of stability and change in fossil brachiopod paleocommunities from the
Pennsylvanian Midcontinent of North America. Although the scale of our dataset should account for this issue and the various analytical approaches we have chosen to employ also address sampling bias in different ways, the possibility of unspecified factors across each environmental category that we cannot assess but that might conceivably influence taxon presence/abundance is a potential caveat to our overall results.

For all analyses, brachiopod occurrences in each formation were first converted to relative abundances (Supplementary Table 2). If a dissimilarity measure was required, we used the Jaccard coefficient (Jaccard 1912) when assessing presence data and the Bray-Curtis dissimilarity measure (Bray and Curtis 1957) to assess taxon abundance data. All analyses were carried out using R v. 3.6.1 (Ihaka and Gentleman 1996).

Analyses of Taxonomic and Abundance Data.Potential dissimilarity between paleocommunities based upon taxonomic and relative abundance data was first visualized using principal coordinates analysis (PCoA), with relative abundance data additionally assessed using detrended correspondence analysis (DCA). To identify whether any differences in paleocommunity composition across the three environmental categories are significant (model 2), permutational multivariate analysis of variance (PERMANOVA), with 100,000 permutations and sampling interval as a fixed factor, was used.

We then directly evaluated all three of our scenarios (models 1-3) by applying the maximum-likelihood framework proposed by Handley et al. (2009) to our relative abundance dataset. This approach is described in full in Handley et al. (2009) and Nagel-Myers et al. (2013), and the interested reader is referred to those publications for a more detailed discussion of this method. In brief, this approach considers each paleocommunity to represent a multinominal observation and then determines which paleocommunities, if any, arise from the same underlying distribution by calculating the probability of observing all of the taxa present in that paleocommunity at the relative proportions at which they occur. Both Akaike's information criterion (AIC) and the Bayesian 
information criterion (BIC) were used to assess model fit.

Analyses of Biodiversity Data.-Differences in biodiversity across the three environmental categories were assessed using diversity accumulation curves with associated rarefaction/ extrapolation (Chao et al. 2014). The first three Hill numbers (see Chao et al. 2014) were used as measures of biodiversity. The first three Hill numbers are taxon richness $(q=0)$, the exponential of Shannon's entropy index $(q=$ $1)$, and the inverse of Simpson's concentration index $(q=2)$. Extrapolation was undertaken up to 40,000 individuals. Pielou's evenness index (PEI; Pielou 1966) was used to measure assemblage evenness for each formation. High evenness reflects an assemblage in which a relatively equal numbers of individuals belong to each taxon, and low evenness indicates that only a small number of taxa make up the majority of the total abundance (Morris et al. 2014). Box-and-whisker plots based upon the Tukey method were generated using PEI results and a Kruskal-Wallis test (Kruskal and Wallis 1952) was used to identify whether significant differences in evenness exist between the three environmental categories.

Both Hill numbers and PEI results were further evaluated by using a likelihood-based framework focused on random-walk models that has previously been employed to identify and fit potential evolutionary models to compilations of ancestor-descendant trait variation (Hunt 2006; Hunt et al. 2015). In addition to evaluating if the model of best fit represents either a random walk or directional change, this approach also assesses for two varieties of stasis. The first, stasis, is defined as uncorrelated, normally distributed variation around a steady mean (Sheets and Mitchell 2001; Hunt et al. 2015). The second, strict stasis, represents instances in which the variance around the long-term mean is zero, such that there is no change between samples. To generate the necessary mean and variance values required to employ this likelihood-based approach, diversity data were bootstrapped (at 100, 1000 and 10,000 replicates) using the boot package in R (Canty 2002). Bootstrapping was undertaken by resampling individual specimen identifications for each paleocommunity to create replicate versions of the relevant paleocommunity with potentially varying taxon abundances. One potential issue with this method is that results are possibly downward-biased, particularly in the case of taxon richness $(q=$ $0)$, as the number of taxa in any one replicate cannot exceed the original sampled values. To assess how this issue may affect our result, for each formation, results of Hill number rarefaction (Chao et al. 2014) were used to determine the possible number of taxa that remain unsampled. The number of conceivable additional taxa stabilized at approximately 20,000 individuals for all formations, indicating that our extrapolation up to 40,000 individuals is more than sufficient to capture potential diversity. These additional taxa were then added to each paleocommunity to allow taxon richness to exceed the observed values (Supplementary Table 3). Abundance values for these hypothetical taxa were deemed to be equal to the observed taxon with the lowest abundance in the relevant formation, based upon the simplifying assumption that, given specimens of these hypothetical taxa were not recovered, their abundance must be equal to or less than all of the taxa actually observed. For both the observed and hypothetical datasets, AIC scores were used to assess model fit.

\section{Results}

Analyses of Taxonomic and Abundance Data Using PCoA and PERMANOVA.-Results of ordination (PCoA and DCA) based upon relative abundance data show almost complete overlap for all three environments (Figs. 3A and 4), a result suggesting model 2 is unlikely to fit our data, as paleocommunities from each environment do not occupy distinct segments of ordination space. However, a definitive conclusion cannot be drawn based on ordination, given the first two axes of our PCoA explain only $\leq 34 \%$ of the total variance. Results of PERMANOVA comparing the three environmental categories and using relative abundance data fall close to the threshold required to demonstrate a statistically significant difference exists between categories (PERMANOVA: $F=1.517, \quad p=$ 0.0513). Performing the same analysis with logtransformed abundance data finds no significant 

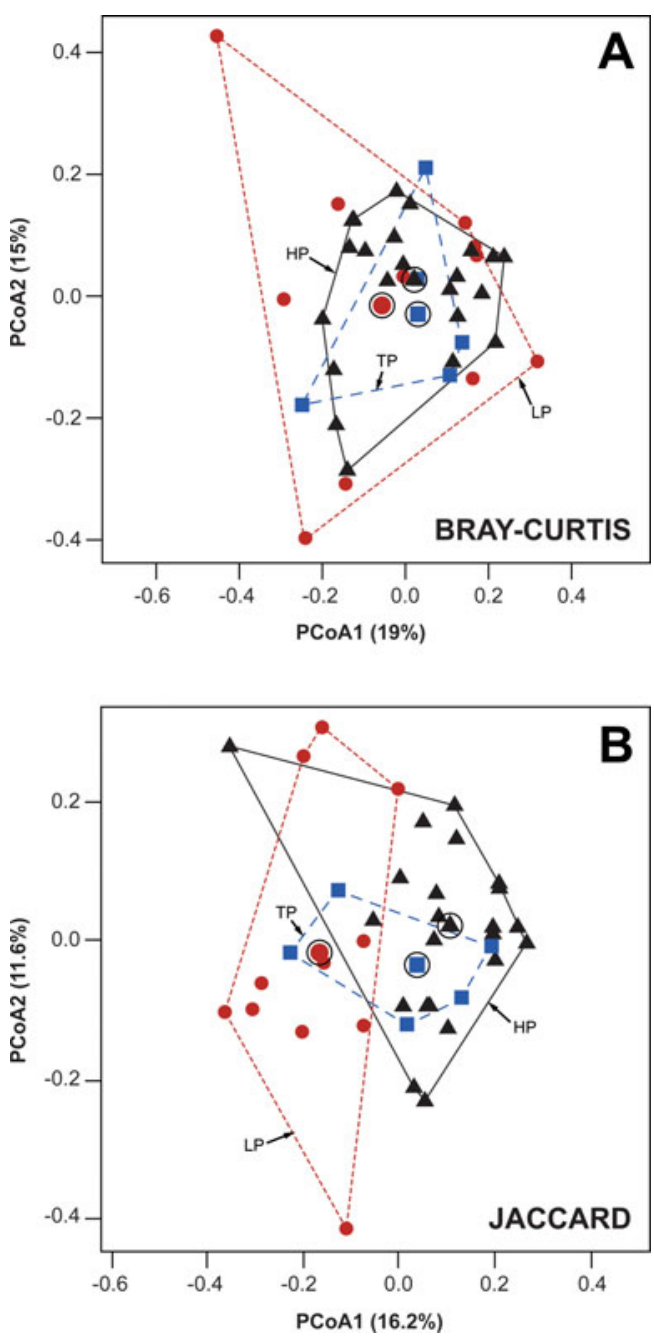

FIGURE 3. Principal coordinates analysis (PCoA) biplot for Pennsylvanian brachiopod paleocommunities from the North American Midcontinent. A, PCoA based upon relative abundance data and using the Bray-Curtis dissimilarity measure. B, PCoA based upon presence data and using the Jaccard similarity coefficient. Symbols represent individual paleocommunities. Circles (red), sea-level lowstand phases (LP); squares (blue), transitory phases (TP); and triangles (black), sea-level highstand phases (HP). Convex hulls outline each of the three environmental categories used in our study. Symbols inside open circles mark the centroid of each convex hull.

difference between categories (PERMANOVA: $F=1.4594, p=0.0722$ ). Because $p>0.05$ for both untransformed and transformed relative abundance data, and given the results of PCoA and DCA, we reject the possibility of model 2 for relative abundance data. This result does not reject either model 1 or 3 . When using only presence data, however, there is a significant difference

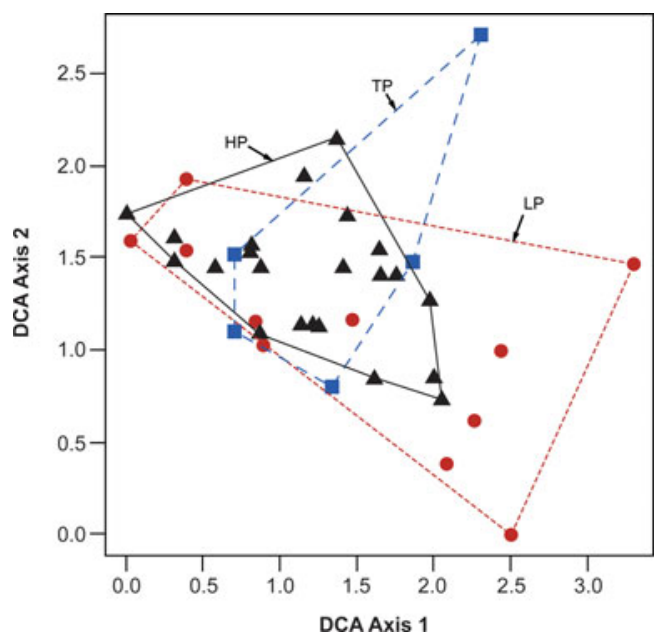

FIGURE 4. Detrended correspondence analysis (DCA) biplot for Pennsylvanian brachiopod paleocommunities from the North American Midcontinent. Symbols represent individual paleocommunities. Circles (red), sea-level lowstand phases (LP); squares (blue), transitory phases (TP); and triangles (black), sea-level highstand phases (HP). Convex hulls outline each of the three environmental categories used in our study.

between environmental categories (PERMANOVA: $F=1.9302, p=0.0024)$, a result that supports model 2. Pairwise comparisons using the Bonferroni method for $p$-value correction indicate this is due to a significant difference between HP and LP paleocommunities (HP vs. LP: $p=$ 0.003), and PCoA results based upon presence data demonstrate a similar pattern (Fig. 3B).

This disparity between results based upon relative abundance data versus those based upon presence data can be attributed to the larger number of rare taxa present in HP paleocommunities. Thirty-one taxa that occur in $\mathrm{HP}$ paleocommunities are never found in LP paleocommunities, and the vast majority of these 31 taxa occur at extremely low abundances (Supplementary Table 2). Taxa that occur at high relative abundances in HP paleocommunities, however, are also present in LP paleocommunities, and vice versa, thus leading to no significant difference between these two environmental categories when relative abundance data are considered.

Analyses of Abundance Data Using AIC and BIC.-A somewhat different picture emerges based upon maximum-likelihood analyses of these data. Maximum-likelihood estimates 
TABLE 1. Rankings for model fit to changes in paleocommunity taxon abundances. Each model is described in detail in the "Analyses" section. For each model, the Akaike information criterion (AIC), Akaike weight, Bayesian information criterion (BIC), and Bayesian weight are provided. Values are rounded to three decimal places.

\begin{tabular}{lcccc}
\hline \hline Model & AIC & Akaike wt. & BIC & Bayesian wt. \\
\hline Model 1 & 23357.140 & 0.000 & 23781.650 & 0.000 \\
Model 2 & 22951.580 & 0.000 & 23800.590 & 0.000 \\
Model 3 & 21918.230 & 1.000 & 22767.240 & 1.000 \\
\hline
\end{tabular}

based upon relative abundance data provide $100 \%$ support for model 3, as indicated by Akaike and Bayesian weights (Table 1). While AIC can favor more complex models, given both AIC and BIC equally support model 3, this result is unlikely to be due to overfitting (Nagel-Myers et al. 2013). This indicates a continually changing relative abundance structure, such that each paleocommunity is considered to be distinct from any other, an unsurprising result, given that individual taxon abundances vary through time and within environmental categories (Supplementary Table 2). The high variance in taxon abundance is such that designating what constitutes a "dominant" taxon remains a somewhat open question. Some taxa certainly always remain rare, but many taxa that are "common" in some formations are extremely rare in others. We also do not see evidence for abundant taxa tracking preferred environments (Bonuso et al. 2002a), with taxon abundance also highly variable within the same environmental category. Thus, these results indicate there is no evidence for stability in paleocommunities either through time or across environments.

Analyses of Biodiversity Data.-Absolute taxonomic richness is highest in HP paleocommunities, which contain 66 of the 69 taxa in our dataset (Fig. 5). Diversity accumulation curve confidence intervals are non-overlapping between HP and LP samples for both $q=0$ and $q=2$. For a fixed sample size, where confidence intervals for Hill number rarefaction/ extrapolation do not overlap, significant difference (at a level of $p<0.05$ ) is guaranteed (Chao et al. 2014). Values for $q=0$ are sensitive to the number of rare taxa, $q=1$ values are sensitive to both rare and abundant taxa, and $q=2$ values are sensitive to only abundant taxa (Chao et al. 2014). The patterns observed for each Hill number therefore indicate that HP assemblages contain larger numbers of rare taxa when compared with TP and, particularly, LP assemblages. PEI values show a similar result (Fig. 6), with lower evenness in HP paleocommunities reflective of the higher number of rare taxa, but there is no significant difference between evenness for the three environmental categories (Kruskal-Wallis chi-squared = $5.43776, p=0.065949)$.

Assessment of diversity values using likelihood-based estimates identify stasis as the best-supported model for the entire metacommunity, which includes all paleocommunities combined (Table 2, Fig. 7). Based upon AIC scores, for all diversity indices, there is greater than $99 \%$ support for overall stasis (but not strict stasis). This means diversity values do fluctuate but remain normally distributed around a mean value. Raising or lowering the number of bootstrap replicates results in no appreciable difference in Akaike weights and no change in which model is best supported (Supplementary Table 4). AIC scores for our hypothetical dataset containing additional potential taxa also identify stasis as the bestsupported model (Supplementary Table 4). Analysis of PEI values using the same methods yields the same result obtained for Hill numbers (Table 2; Supplementary Table 4).

\section{Discussion}

Our results highlight the importance of considering multiple approaches when evaluating the possibility of community stability in the fossil record, as different approaches may yield divergent results. For instance, multivariate analyses based on relative abundance data reject the possibility of a distinct and discernible paleocommunity associated with each environmental category, suggesting paradoxically that either stasis prevails through time and across environments (model 1 ) or that no paleocommunity stability is manifest at all (model 3). Yet multivariate analysis of presence data suggests a moderate form of stasis, wherein paleocommunities are homogenous within environmental categories but heterogeneous 

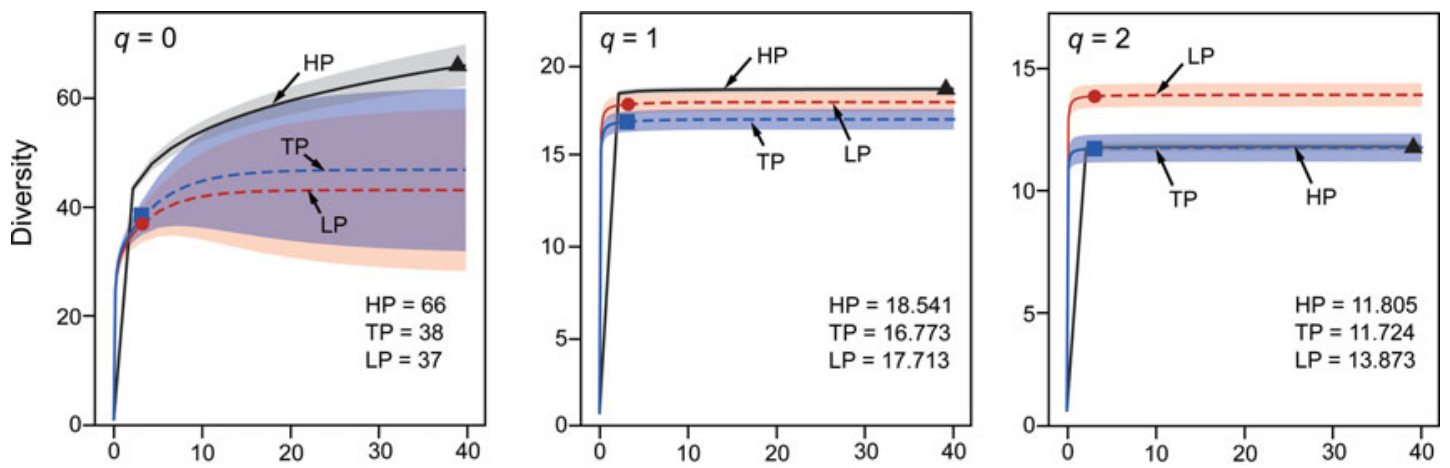

Number of individuals(,000s)

FIGURE 5. Sample-size-based rarefaction (solid line) and extrapolation (dashed lines) for Pennsylvanian brachiopod diversity. Hill number $q=0$ (left panel), $q=1$ (middle panel), and $q=2$ (right panel). Red, sea-level lowstand phases (LP); blue, transitory phases (TP); and black, sea-level highstand phases (HP). Reference sample for each sampling interval is indicated by a solid symbol (LP, circle; TP, square; HP, triangle). Shaded areas represent confidence intervals for each environmental category. Overall Hill number values for each environmental category are listed in the bottom right corner of each plot.

between categories (model 2). A maximum likelihood-based assessment of relative abundance data, however, provides unequivocal support for repeated turnover (model 3), refuting the possibility of paleocommunity stasis. Finally, if the precise taxonomic identity of representatives of any paleocommunity are not considered, and instead diversity is the

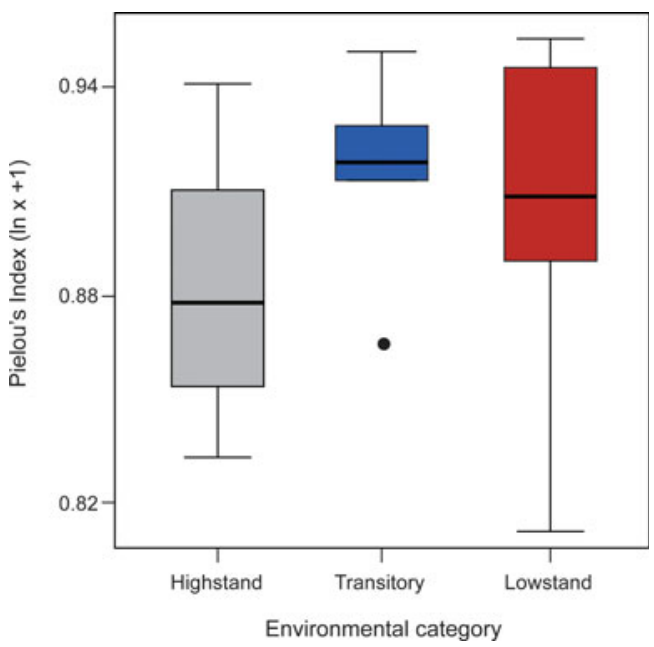

FIGURE 6. Box plots of Pielou's evenness index scores for each environmental category. Dark band inside box= median. Whiskers $= \pm 1.5 *$ interquartile range (IQR). Solid circle represents sample site that falls outside the range of whiskers. The lower whisker for the transitory environmental category is equal to the lower bound of the IQR for that category. focus, stasis (model 1) is the returned result. This incongruence between our various results, while seemingly problematic, reflects the varying methods we employ to assess for stability at different positions on the ecological hierarchy (sensu Jørgensen and Nielsen 2013) and that conceivably distinct processes may drive the patterns observed at each scale.

At the scale of individual brachiopod paleocommunities, it is evident that abiotic change is an important driver of paleocommunity structure and that paleocommunity turnover is linked to each phase of major transgressive/ regressive events. Importantly, the composition and underlying abundance distribution of any new paleocommunity may or may not resemble the paleocommunity that was present during a previous phase, even when that phase is representative of the same environmental category. Therefore, the net pattern does not resemble that of a Markov process, in that the structure of a paleocommunity is not dependent upon the composition of the previous paleocommunity. Instead, each paleocommunity seemingly is formed via the luck of the draw and/or the exigencies of recruitment or survival. This lack of stability suggests that there is no obvious evidence for habitat tracking (Brett and Baird 1995; Olszewski and Patzkowsky 2001a) at the scale observed, as brachiopod paleocommunities with consistent taxonomic compositions do not 
TABLE 2. Maximum-likelihood parameter estimates for diversity values. AICc values (AICc = sample-size adjusted AIC values) and Akaike weights are listed for four models: GRW (general random walk), URW (unbiased random walk), Stasis, and S. Stasis (strict stasis). Definitions for each of these four models are discussed in the "Analyses" section. Taxon richness, Shannon's entropy, and inverse Simpson's represent the first three Hill numbers respectively $(q=0-2)$. Values are rounded to three decimal places. For all indices, stasis is the best-fitting model, with greater than $99 \%$ support.

\begin{tabular}{|c|c|c|c|c|c|c|c|c|}
\hline \multirow[b]{2}{*}{ Diversity index } & \multicolumn{4}{|c|}{$\mathrm{AICc}$} & \multicolumn{4}{|c|}{ Akaike wt. } \\
\hline & GRW & URW & Stasis & S. Stasis & GRW & URW & Stasis & S. Stasis \\
\hline Taxon richness & 289.648 & 287.346 & 276.295 & $290,301.983$ & 0.001 & 0.004 & 0.995 & 0.000 \\
\hline Shannon's entropy & 218.419 & 216.133 & 201.876 & $111,215.594$ & 0.000 & 0.001 & 0.999 & 0.000 \\
\hline Inverse Simpson's & 194.285 & 191.989 & 178.606 & $68,225.743$ & 0.000 & 0.001 & 0.999 & 0.000 \\
\hline Pielou's evenness & -74.66 & -77.011 & -89.463 & $33,837.468$ & 0.001 & 0.002 & 0.997 & 0.000 \\
\hline
\end{tabular}

re-emerge in subsequent formations in association with shifts in environment. An absence of habitat tracking partially conflicts with previous work on Midcontinent paleocommunities, which identified both habitat tracking and de novo paleocommunity formation (Holterhoff 1996; Olszewski and Patzkowsky 2001a). However, this previous work focused on alternate taxa and a narrower temporal and geographic scale, which may account for the differing result.

Given that our study focuses on a relatively broad geographic region and temporal interval, it is not possible to discern whether changes in taxonomic composition were also happening at a scale below the level of assemblages within formations. Because our paleocommunities represent a metacommunity concept that incorporates significant time averaging, it is logical to assume that some amount of taxonomic turnover is also happening at smaller spatial and temporal scales. Analyzing such change would be both important and valuable but at present is not possible, given the stratigraphic resolution of our data. Thus, it is important to reiterate that the pattern of de novo paleocommunity formation we uncover is documented at the level of paleocommunities sensu Bennington and Bambach (1996), and considering smaller spatial and temporal intervals could lead to additional or alternate conclusions. However, it is also important to recognize that thanks to the detailed sedimentological and stratigraphic perspective available for the region (e.g., Heckel 2008, 2013), it is clear that different formations connote substantially different paleoenvironmental conditions and the scale of environmental change that occurs between formations far exceeds the environmental fluctuations that occur within any one formation. At its most extreme, the boundary between formations represents a sequence boundary (Heckel 2008): an erosional surface representative of subaerial exposure and a time of maximum environmental perturbation. The scale of environmental change between formations is such that significant biological turnover is most likely greater during the transition from one formation to the next than within any one formation. Undoubtedly, important environmental changes do occur within formations, and consideration of the fluctuations in community structure that may be associated with these changes could help further expand the notion of why it is important to consider the nature of stability and change in ecological assemblages at several hierarchical levels, but at the present time and in this study system, this is not possible.

Despite the taxonomic constituents of paleocommunities being highly variable, there seem to be limits on taxon richness for each paleoenvironmental category (Fig. 7, Supplementary Table 2). This implies rules for taxon packing in the Pennsylvanian brachiopod paleocommunities of the Midcontinent. Consistent patterns of taxon packing in communities have been posited in several classic treatises in ecology (e.g., MacArthur and Wilson 1967; Hubbell 2001). In the specific case of our brachiopod paleocommunities, differences in taxon richness between paleoenvironmental categories may reflect limitations on the available substrate needed for individual brachiopod larva to successfully develop into adults (Fürsich and Hurst 1974; Bonuso and Bottjer 2006; Topper et al. 2015). Once available physical space is exhausted, there could be exclusion based upon incumbency (Valentine et al. 2008), with the 

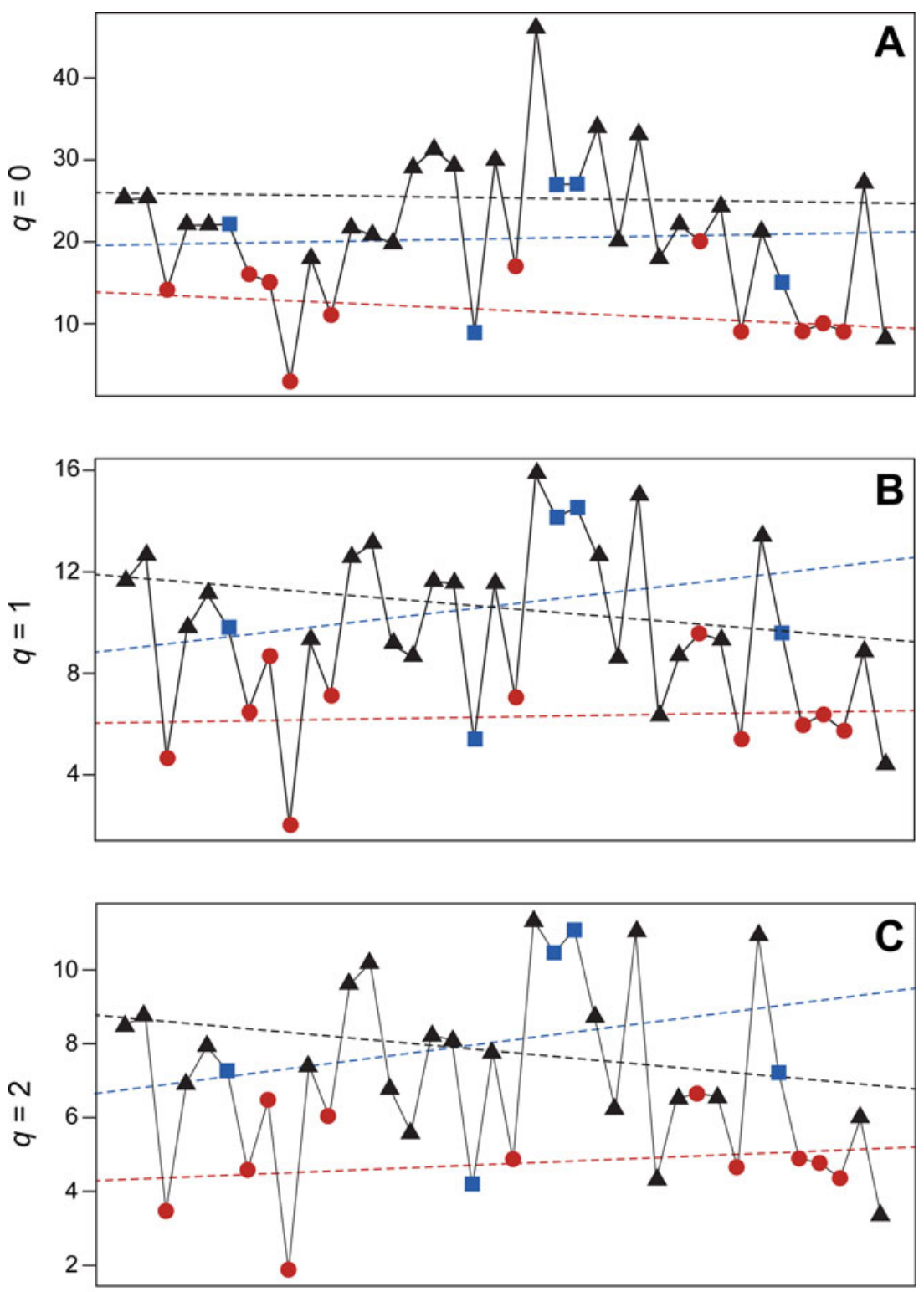

Relative Time

FIGURE 7. Diversity values for Pennsylvanian brachiopod paleocommunities of the North American Midcontinent. A, Taxon richness $(q=0)$; B, exponential of Shannon's entropy index $(q=1)$; C, inverse of Simpson's concentration index $(q=2)$. Circles (red), sea-level lowstand phases (LP); squares (blue), transitory phases (TP); and triangles (black), sea-level highstand phases (HP). Dashed lines represent linear line of best fit for each diversity index and environmental category (as indicated). For all indices, stasis is the best-fitting model.

upper limit on the number of taxa present in any one paleocommunity correlated with available habitat. The quantity of available habitat would expand with increasing water depth (Olszewski and Patzkowsky 2003), as a greater part of the shelf-slope becomes available for occupation. Energy budgets and associated per capita metabolic activity may also contribute to the observed pattern. Metabolic activity in any one community/paleocommunity has been demonstrated to exhibit remarkable stability, despite species turnover and environmental 
disruption (Finnegan et al. 2011; Strotz et al. 2018a). This stability can be achieved through limits on maximum species richness, exclusion of copious taxa with higher metabolic demands, limits on taxon abundance, or some combination of all three (Strotz et al. 2018a). The limits on taxon packing we identify in the Pennsylvanian Midcontinent may thus also reflect physiological controls that limit how many species can be maintained in any single community, with distinct environments able to sustain a differing number of species due to differences in energy availability (Glazier 1987; Strotz et al. 2018a).

An even more profound pattern of paleocommunity stability emerges when the fauna is assessed in its totality, with all diversity metrics exhibiting stasis for the entire study interval (Table 2, Fig. 7). This suggests $\gamma$-diversity, defined as the total species diversity in a landscape (Whittaker 1960; Whittaker et al. 2001), remains unchanged. Perhaps this is to be expected, given there is no evidence of either extinction or speciation in the regional biota (Olszewski and Patzkowsky 2001a). Thus, when populations of a species disappear locally due to environmental and/or physical disruption, they still can possibly reappear in one or more subsequent paleocommunities. Moreover, any environmental changes are invariably reversed in a subsequent cyclothem. The minimal impact on $\gamma$-diversity may reflect the presence of ample refugia (Stewart et al. 2010), allowing taxa to persist in the face of environmental change.

When considered together, these patterns of paleocommunity structure provide the necessary evidence to reconstruct the macroecological dynamics in Pennsylvanian brachiopod faunas from the Midcontinent Basin of North America. As sea level rises, newly available habitat is randomly seeded by migrating taxa in the form of essentially arbitrary pulls from the greater pool of $\gamma$-diversity. Ultimately $\alpha$-diversity, represented in our study by the total taxon richness in any one paleocommunity, becomes saturated once the carrying capacity of the relevant paleoenvironment is reached, and any taxa that subsequently attempt to join the paleocommunity are excluded. This somewhat resembles "environmental selection," as proposed by Bambach
(1994) and also parallels the mechanisms for recruitment as implemented in the theory of island biogeography (MacArthur and Wilson 1963, 1967), although operating at a much larger scale. Taxa that successfully colonize may have intrinsic advantages such as increased dispersal capacity or greater fecundity (Clark and Ji 1995), but fluctuations in rank abundance (Supplementary Table 2) suggest stochastic processes, such as vagaries in recruitment dynamics and fluctuations in the import of biotic interactions (Miller 1986) may be just as important, at least in the long-term realm of these paleocommunities. Once a regression event begins, paleocommunity turnover recommences. As the regressive phase progresses, taxa may persist due to higher levels of abundance, because their niche more closely corresponds to current conditions, or because they simply have not yet been culled. At sealevel lowstand, $\alpha$-diversity again stabilizes until such time as a transgressive phase commences and turnover begins anew.

With each cyclothem, this pattern of diversity ramp-up and drawdown is repeated, resulting in no net ecological change over time. As $\gamma$-diversity remains unaffected, this cycle can potentially persist over very long periods of time (Buzas and Culver 1994). This pattern can be usefully viewed in the context of Hubbell's (2001) unified neutral theory of biodiversity and biogeography, in which $\gamma$-diversity can be considered equivalent to Hubbell's (2001) metacommunity, representing a stable pool of potential immigrants that can seed local communities as suitable niche space is created (Rosindell et al. 2011). In this context, random taxa from the metacommunity form new paleocommunities that "replace" the paleocommunity that was previously present. Individual paleocommunities are thus essentially neutral, with their diversity fixed by the carrying capacity of the paleoenvironment. In our case, however, we are proposing repeated wholesale community replacement, a rather more drastic scenario than the attritional replacement of individuals within local communities proposed by Hubbell's unified neutral theory (Hubbell 2001; Rosindell et al. 2011).

The pattern of stability in the face of constant change we identify is potentially analogous to 
results from modern marine communities as they recover from disruptive events over much shorter timescales. For example, foraminifera communities subjected to disruption by tropical cyclones rapidly re-established previous species distribution patterns, with no loss of biodiversity, once the cyclone passed (Strotz et al. 2016). Evidence indicates, however, that these communities never reach steady state and exist in a permanent state of intermediate recovery (Strotz et al. 2016). Similar patterns have been observed for coral communities (Richards et al. 2008) and fish communities (Planes et al. 2005) that were removed from parts of Pacific atolls multiple times by the nuclear testing programs of the late twentieth century. Given these events are on much shorter timescales than those experienced by the paleocommunities we assess, it is not clear whether they represent similar phenomena, such that a direct connection exists between the various ecological scales, or instead are merely analogous and fundamentally distinct, and thereby driven by different sets of ecological processes (see discussion of ecological hierarchies in Valentine 1970; Eldredge and Salthe 1984; Eldredge 1986). Considering this issue of scale is necessary in any paleoecological investigation for a variety of reasons, including because paleocommunities are not directly analogous to biological communities (Bennington and Bambach 1996). In particular, while the constituent taxa of a paleocommunity may occupy the same geographic space, they may not be continually coterminous in time and thus may not have interacted ecologically. Yet, just as fossil species differ from the extant biological populations that are the purview of biology but still represent a unit of biological import (Strotz and Allen 2013), so paleocommunities still represent a cohesive ecological unit that connects hierarchically to extant communities (Pandolfi 2002; DiMichele et al. 2004).

The stability in $\gamma$-diversity through time we observe aligns with the concept of coordinated stasis, concurring with both initial definitions and subsequent works (e.g., Brett and Baird 1995; Morris et al. 1995; Bonuso et al. 2002a,b; Ivany et al. 2009). However, we cannot identify the "stasis packages" that according to Brett et al. (1996) are the benchmark of "true" coordinated stasis. This is because, even though a large proportion of the Pennsylvanian Midcontinent brachiopod taxa persist through time, they do not cohere into continuous paleocommunities or biofacies (sensu Boucot 1975; Brett and Baird 1995; Morris et al. 1995). Thus, the detailed ecological stasis typical of coordinated stasis is lacking. Further, and associated with this, we did not find evidence for ecological locking (Morris et al. 1995), a potential causal mechanism for coordinated stasis, as taxonomic composition does not persist through environmental shifts and taxon abundance is highly variable. While $\gamma$-diversity does persist, it is a metaconcept that combines multiple paleocommunities, and thus the interaction that is a key element of ecological locking is difficult to identify. This lack of evidence for coordinated stasis or ecological locking, in comparison to archetypal studies on both these concepts centering on the Hamilton Group of New York State (Brett and Baird 1995; Morris et al. 1995), may possibly be at least partly attributed to differences in temporal and spatial scale between our study and previous work on the Hamilton Group, as well as key differences in the tectonic setting of the Hamilton Group versus the Pennsylvanian Midcontinent (Brett and Baird 1995; Heckel 2013). It is also judicious that we consider our results in the context of the important topic that Bennington and Bambach (1996) addressed: whether recognizing paleocommunity stability through time entails that the same individual paleocommunities (with individuals defined sensu Hull [1976]) persisted over long intervals of time, or instead only generally similar ones persisted. Given the absence of evidence for persistent biofacies and ecological locking, the brachiopod paleocommunities in the Pennsylvanian Midcontinent that we considered seem to be representatives of classes (Hull 1976; Wiley 1978); they resemble one another but were not single, historically connected individuals.

The repeated cycle of turnover at the formation level we identify also parallels aspects of the turnover pulse hypothesis (Vrba 1985, 1993), wherein changes in the composition of paleocommunities are initiated by changes in 
the physical environment. Without environmental shifts of significant magnitude, changes in a paleocommunity are nondirectional around a mean configuration. This is because, although unremitting biotic interactions can generate shifts in fitness at the population level, as per a qualified definition of the Red Queen hypothesis (Strotz et al. 2018b), because these shifts do not affect all populations equally, they appear as stasis at the level of species in communities. Only a more complete transformation of the physical environment can lead to assemblage turnover. However, over longer timescales and at higher scales of the ecological hierarchy (e.g., $\gamma$-diversity), we observe stasis. This may partly be explained by considering the sloshing bucket hypothesis (Eldredge 2003, 2008). This hypothesis posits that disruptions can result in community breakdown but may not be sufficient to lead to full ecosystem collapse. As long as the relevant threshold of disruption is never reached, continued paleocommunity reconstitution after each episode of environmental change is highly likely. In the particular case considered herein, there are two end-member paleocommunities (HP and LP) that are repeatedly able to re-form because the environmental disruption experienced by the greater $\gamma$-species pool is never enough to cause its complete ecological breakdown. It is not possible, though, to identify the threshold at which community collapse is likely assured, that is, what causes the bucket to get kicked over. This is because we are only considering a time interval that represents part of a stable faunal package (Brett and Baird 1995; Morris et al. 1995; Brett et al. 1996; Olszewski and Patzkowsky 2001b).

Miller (1986) proposed the concept of "community replacement" for patterns of community turnover identified in the fossil record. Shifts in the environmental regime are the primary driver of community replacement, leading to wholesale changes in speciesabundance distributions. Importantly, Miller (1986) proposed that community replacement occupied a higher hierarchical level than ecological changes driven by biotic interactions and that, given the time frames involved, paleoecologists need to carefully consider the hierarchical scale being observed. Pandolfi
(2002) also argued that the hierarchical scale being considered has a marked effect on how ecological dynamics in fossil assemblages are interpreted, and our results reiterate this important contention. In particular, in some respects, paleocommunity stasis can be hard to discern when it is assessed via patterns of species association and relative abundance. However, when it comes to patterns of diversity, paleocommunity stability can be manifest even where taxonomic turnover is evident. It would thus seem that, when it comes to identifying stability in community structure through time, sometimes the names don't matter but the numbers do.

\section{Conclusions}

In this study we closely examine the Carboniferous brachiopod paleocommunities from the Midcontinent of North America to determine whether paleocommunity structure can remain stable despite recurring shifts in environmental setting. We show that marked shifts in both taxonomic composition and the associated abundance of taxa provide little evidence for obdurate ecological stasis at the level of paleocommunities. However, close examination of diversity patterns identifies stability exists at what constitutes a different ecological scale, as per Eldredge's (2003) sloshing bucket hypothesis. This suggests that rules operating at higher levels in the ecological hierarchy may allow for ecological stability even in the face of constant disequilibrium. Based on these results, we advocate for careful consideration of hierarchical scale when interpreting the ecological dynamics of fossil assemblages.

\section{Acknowledgments}

We thank N. López Carranza and R. LaVine for comments on an earlier version of this manuscript and J. Kimmig for assistance with collections-related matters. We would also like to thank W. Kiessling in his role as editor for Paleobiology, along with M. Clapham and two anonymous reviewers for their comments and suggestions that helped to improve the final version of our paper. Financial support for this project was provided by NSF EF 
1206757 and DBI 1602067. This material is based upon work (by B.S.L.) supported while working at the National Science Foundation.

\section{Literature Cited}

Antell, G. S., W. Kiessling, M. Aberhan, and E. E. Saupe. 2020. Marine biodiversity and geographic distributions are independent on large scales. Current Biology 30:115-121.

Baldeck, C. A., K. E. Harms, J. B. Yavitt, R. John, B. L. Turner, R. Valencia, H. Navarrete, S. Bunyavejchewin, S. Kiratiprayoon, and A. Yaacob. 2013. Habitat filtering across tree life stages in tropical forest communities. Proceedings of the Royal Society of London B 280:20130548.

Balmford, A., A. Lyon, and R. M. Lang. 2000. Testing the highertaxon approach to conservation planning in a megadiverse group: the macrofungi. Biological Conservation 93:209-217.

Balseiro, D. 2016. Compositional turnover and ecological changes related to the waxing and waning of glaciers during the late Paleozoic ice age in ice-proximal regions (Pennsylvanian, western Argentina). Paleobiology 42:335-357.

Bambach, R. 1994. The null hypothesis for community stability and recurrence - environmental selection of adapted organisms. Geological Society of America Abstracts with Programs 26:A519.

Bell, G., and S. Collins. 2008. Adaptation, extinction and global change. Evolutionary Applications 1:3-16.

Bennington, J., and R. Bambach. 1996. Statistical testing for paleocommunity recurrence: are similar fossil assemblages ever the same? Palaeogeography, Palaeoclimatology, Palaeoecology 127:107-133.

Bonelli, J. R., C. E. Brett, A. I. Miller, and J. B. Bennington. 2006. Testing for faunal stability across a regional biotic transition: quantifying stasis and variation among recurring coral-rich biofacies in the Middle Devonian Appalachian Basin. Paleobiology 32:20-37.

Bonuso, N., and D. J. Bottjer. 2006. A quantitative study of benthic faunal patterns within the Pennsylvanian and Early Permian. Palaios 21:316-324

Bonuso, N., C. R. Newton, J. C. Brower, and L. C. Ivany. 2002a. Does coordinated stasis yield taxonomic and ecologic stability? Middle Devonian Hamilton Group of central New York. Geology 30:1055-1058.

Bonuso, N., C. R. Newton, J. C. Brower, and L. C. Ivany. 2002b. Statistical testing of community patterns: uppermost Hamilton Group, Middle Devonian (New York State: USA). Palaeogeography, Palaeoclimatology, Palaeoecology 185:1-24.

Boucot, A. 1975. Standing diversity of fossil groups in successive intervals of geologic time viewed in the light of changing levels of provincialism. Journal of Paleontology 49:1105-1111.

Bray, J. R., and J. T. Curtis. 1957. An ordination of the upland forest communities of southern Wisconsin. Ecological Monographs 27:325-349.

Brett, C. E., and G. C. Baird. 1995. Coordinated stasis and evolutionary ecology of Silurian to Middle Devonian faunas in the Appalachian Basin. Pp. 285-315 in D. Erwin and R. Anstey, eds. New approaches to speciation in the fossil record. Columbia University Press, New York.

Brett, C. E., L. C. Ivany, and K. M. Schopf. 1996. Coordinated stasis: an overview. Palaeogeography, Palaeoclimatology, Palaeoecology 127:1-20.

Buzas, M. A., and S. J. Culver. 1994. Species pool and dynamics of marine paleocommunities. Science 264:1439-1441.

Canty, A. J. 2002. Resampling methods in R: the boot package. Newsletter of the R Project 2/3:2-7

Chao, A., C.-H. Chiu, and L. Jost. 2014. Unifying species diversity, phylogenetic diversity, functional diversity, and related similarity and differentiation measures through Hill numbers. Annual Review of Ecology, Evolution, and Systematics 45:297324.

Clapham, M. E., and D. J. Bottjer. 2007. Permian marine paleoecology and its implications for large-scale decoupling of brachiopod and bivalve abundance and diversity during the Lopingian (Late Permian). Palaeogeography, Palaeoclimatology, Palaeoecology 249:283-301.

Clark, J. S., and Y. Ji. 1995. Fecundity and dispersal in plant populations: implications for structure and diversity. American Naturalist 146:72-111.

Cleland, H. F. 1903. A study of the fauna of the Hamilton Formation of the Cayuga Lake section in central New York. United States Geological Survey Bulletin 206:1-122.

Condamine, F. L., J. Rolland, and H. Morlon. 2013. Macroevolutionary perspectives to environmental change. Ecology Letters 16:72-85.

Connell, J. H., and R. O. Slatyer. 1977. Mechanisms of succession in natural communities and their role in community stability and organization. American Naturalist 111:1119-1144.

DiMichele, W. A., A. K. Behrensmeyer, T. Olszewski, C. C. Labandeira, J. M. Pandolfi, S. L. Wing, and R. Bobe. 2004. Long-term stasis in ecological assemblages: evidence from the fossil record. Annual Review of Ecology, Evolution, and Systematics 35:285-322.

Eldredge, N. 1986. Information, economics, and evolution. Annual Review of Ecology and Systematics 17:351-369.

Eldredge, N. 2001. The nature and origin of supraspecific taxa revisited: with special reference to Trilobita. Pp. 341-375 in J. M. Adrain, G. D. Edgecombe, and B. S. Lieberman, eds. Fossils, phylogeny, and form: an analytical approach. Kluwer Academic, New York.

Eldredge, N. 2003. The sloshing bucket: how the physical realm controls evolution. Pp. 3-32 in J. Crutchfield and P. Schuster, eds. Towards a comprehensive dynamics of evolution - exploring the interplay of selection, neutrality, accident, and function. Oxford University Press, New York.

Eldredge, N. 2008. Hierarchies and the sloshing bucket: toward the unification of evolutionary biology. Evolution: Education and Outreach 1:10-15.

Eldredge, N., and S. N. Salthe. 1984. Hierarchy and evolution. Oxford Surveys in Evolutionary Biology 1:184-208.

Felton, R. M., and P. H. Heckel. 1996. Small-scale cycles in Winterset Limestone Member (Dennis Formation, Pennsylvanian of northern Midcontinent) represent "phased regression." Pp. 389-397 in B. J. Witzke, G. A. Ludvigson, and J. Day, eds. Paleozoic sequence stratigraphy: views from the North American craton. Geological Society of America Special Paper 306.

Finnegan, S., C. M. McClain, M. A. Kosnik, and J. L. Payne. 2011. Escargots through time: an energetic comparison of marine gastropod assemblages before and after the Mesozoic Marine Revolution. Paleobiology 37:252-269.

Fürsich, F. T., and J. M Hurst. 1974. Environmental factors determining the distribution of brachiopods. Palaeontology 17:879-900.

Gallien, L. 2017. Intransitive competition and its effects on community functional diversity. Oikos 126:615-623.

Glazier, D. S. 1987. Energetics and taxonomic patterns of species diversity. Systematic Zoology 36:62-71.

Grabau, A. W. 1898. Geology and palaeontology of Eighteen Mile Creek and the Lake Shore sections of Erie County, New York, Part 2: palaeontology. Buffalo Society of Natural Sciences Bulletin 6:92-403.

Grelle, C. E. V. 2002. Is higher-taxon analysis an useful surrogate of species richness in studies of Neotropical mammal diversity? Biological Conservation 108:101-106.

Hairston, N. G., F. E. Smith, and L. B. Slobodkin. 1960. Community structure, population control, and competition. American Naturalist 94:421-425. 
Handley, J. C., H. D. Sheets, and C. E. Mitchell. 2009. Probability models for stasis and change in paleocommunity structure. Palaios 24:638-649.

Heckel, P. H. 1986. Sea-level curve for Pennsylvanian eustatic marine transgressive-regressive depositional cycles along midcontinent outcrop belt, North America. Geology 14:330-334.

Heckel, P. H. 1994. Evaluation of evidence for glacio-eustatic control over marine Pennsylvanian cyclothems in North America and consideration of possible tectonic effects. Pp. 65-87 in J. M. Dennison and F. R. Ettensohn, eds. Tectonic and eustatic controls on sedimentary cycles. SEPM Concepts in Sedimentology and Paleontology 4.

Heckel, P. H. 2008. Pennsylvanian cyclothems in Midcontinent North America as far-field effects of waxing and waning of Gondwana ice sheets. Pp. 275-290 in C. R. Fielding, T. D. Frank, and J. L. Isbell, eds. Resolving the late Paleozoic ice age in time and space. Geological Society of America Special Paper 441.

Heckel, P. H. 2013. Pennsylvanian stratigraphy of northern Midcontinent Shelf and biostratigraphic correlation of cyclothems. Stratigraphy 10:3-40.

Holterhoff, P. F. 1996. Crinoid biofacies in Upper Carboniferous cyclothems, midcontinent North America: faunal tracking and the role of regional processes in biofacies recurrence. Palaeogeography, Palaeoclimatology, Palaeoecology 127:47-81.

Hubbell, S. P. 2001. The unified neutral theory of biodiversity and biogeography. Princeton University Press, Princeton, N.J.

Hull, D. L. 1976. Are species really individuals? Systematic Zoology 25:174-191.

Hunt, G. 2006. Fitting and comparing models of phyletic evolution: random walks and beyond. Paleobiology 32:578-601.

Hunt, G., M. J. Hopkins, and S. Lidgard. 2015. Simple versus complex models of trait evolution and stasis as a response to environmental change. Proceedings of the National Academy of Sciences USA 112:4885-4890.

Ihaka, R., and R. Gentleman. 1996. R: a language for data analysis and graphics. Journal of Computational and Graphical Statistics 5:299-314.

Ivany, L. C. 1996. Coordinated stasis or coordinated turnover? Exploring intrinsic vs. extrinsic controls on pattern. Palaeogeography, Palaeoclimatology, Palaeoecology 127:239-256.

Ivany, L. C., C. E. Brett, H. L. Wall, P. D. Wall, and J. C. Handley. 2009. Relative taxonomic and ecologic stability in Devonian marine faunas of New York State: a test of coordinated stasis. Paleobiology 35:499-524.

Jablonski, D., and J. J. Sepkoski Jr. 1996. Paleobiology, community ecology, and scales of ecological pattern. Ecology 77:1367-1378.

Jaccard, P. 1912. The distribution of the flora in the alpine zone. 1. New Phytologist 11:37-50.

Jackson, S. T., and D. F. Sax. 2010. Balancing biodiversity in a changing environment: extinction debt, immigration credit and species turnover. Trends in Ecology and Evolution 25:153-160.

Jørgensen, S. E., and S. N. Nielsen. 2013. The properties of the ecological hierarchy and their application as ecological indicators. Ecological Indicators 28:48-53.

Kruskal, W. H., and W. A. Wallis. 1952. Use of ranks in onecriterion variance analysis. Journal of the American Statistical Association 47:583-621.

Lieberman, B. S., and G. Kloc. 1997. Evolutionary and biogeographic patterns in the Asteropyginae (Trilobita, Devonian). Bulletin of the American Museum of Natural History 232:1-127.

MacArthur, R. H., and E. O. Wilson. 1963. An equilibrium theory of insular zoogeography. Evolution 17:373-387.

MacArthur, R. H., and E. O. Wilson. 1967. The theory of island biogeography. Princeton University Press, Princeton, N.J.

Magurran, A. E., and B. J. McGill. 2011. Biological diversity: frontiers in measurement and assessment. Oxford University Press, Oxford.
Miller, A. I. 1997. Coordinated stasis or coincident relative stability? Paleobiology 23:155-164.

Miller, W., III. 1986. Paleoecology of benthic community replacement. Lethaia 19:225-231.

Morris, E. K., T. Caruso, F. Buscot, M. Fischer, C. Hancock, T. S. Maier, T. Meiners, C. Müller, E. Obermaier, and D. Prati. 2014. Choosing and using diversity indices: insights for ecological applications from the German Biodiversity Exploratories. Ecology and Evolution 4:3514-3524.

Morris, P. J., L. C. Ivany, K. M. Schopf, and C. E. Brett. 1995. The challenge of paleoecological stasis: reassessing sources of evolutionary stability. Proceedings of the National Academy of Sciences USA 92:11269-11273.

Mougi, A., and M. Kondoh. 2012. Diversity of interaction types and ecological community stability. Science 337:349-351.

Nagel-Myers, J., G. P. Dietl, J. C. Handley, and C. E. Brett. 2013. Abundance is not enough: the need for multiple lines of evidence in testing for ecological stability in the fossil record. PLoS ONE 8: e63071.

Olszewski, T. D., and M. E. Patzkowsky. 2001a. Evaluating taxonomic turnover: Pennsylvanian-Permian brachiopods and bivalves of the North American Midcontinent. Paleobiology 27:646-668.

Olszewski, T. D., and M. E. Patzkowsky. 2001b. Measuring recurrence of marine biotic gradients: a case study from the Pennsylvanian-Permian Midcontinent. Palaios 16:444-460.

Olszewski, T. D., and M. E. Patzkowsky. 2003. From cyclothems to sequences: the record of eustasy and climate on an icehouse epeiric platform (Pennsylvanian-Permian, North American Midcontinent). Journal of Sedimentary Research 73:15-30.

Paine, R. T. 1969. A note on trophic complexity and community stability. American Naturalist 103:91-93.

Pandolfi, J. 2002. Coral community dynamics at multiple scales. Coral Reefs 21:13-23.

Patzkowsky, M. E., and S. M. Holland. 1997. Patterns of turnover in Middle and Upper Ordovician brachiopods of the eastern United States: a test of coordinated stasis. Paleobiology 23:420-443.

Pielou, E. C. 1966. The measurement of diversity in different types of biological collections. Journal of Theoretical Biology 13:131-144.

Planes, S., R. Galzin, J. Bablet, and P. Sale. 2005. Stability of coral reef fish assemblages impacted by nuclear tests. Ecology 86:2578-2585.

Reymond, C. E., M. Bode, W. Renema, and J. Pandolfi. 2011. Ecological incumbency impedes stochastic community assembly in Holocene foraminifera from the Huon Peninsula, Papua New Guinea. Paleobiology 37:670-685.

Richards, Z. T., M. Beger, S. Pinca, and C. C. Wallace. 2008. Bikini Atoll coral biodiversity resilience five decades after nuclear testing. Marine Pollution Bulletin 56:503-515.

Roopnarine, P. D., K. Angielczyk, A. Weik, and A. Dineen. 2019. Ecological persistence, incumbency and reorganization in the Karoo Basin during the Permian-Triassic transition. EarthScience Reviews 189:244-263.

Rosindell, J., S. P. Hubbell, and R. S. Etienne. 2011. The unified neutral theory of biodiversity and biogeography at age ten. Trends in Ecology and Evolution 26:340-348.

Rudwick, M. J. 1970. Living and fossil brachiopods. Hutchinson University Library, London.

Rundell, R. J., and T. D. Price. 2009. Adaptive radiation, nonadaptive radiation, ecological speciation and nonecological speciation. Trends in Ecology and Evolution 24:394-399.

Santini, L., J. Belmaker, M. J. Costello, H. M. Pereira, A. G. Rossberg, A. M. Schipper, S. Ceaușu, M. Dornelas, J. P. Hilbers, and J. Hortal. 2017. Assessing the suitability of diversity metrics to detect biodiversity change. Biological Conservation 213:341-350. 
Sheets, H. D., and C. E. Mitchell. 2001. Uncorrelated change produces the apparent dependence of evolutionary rate on interval. Paleobiology 27:429-445.

Stewart, J. R., A. M. Lister, I. Barnes, and L. Dalén. 2010. Refugia revisited: individualistic responses of species in space and time. Proceedings of the Royal Society of London B 277:661671.

Strotz, L. C., and A. P. Allen. 2013. Assessing the role of cladogenesis in macroevolution by integrating fossil and molecular evidence. Proceedings of the National Academy of Sciences USA 110:2904-2909.

Strotz, L. C., B. L. Mamo, and D. Dominey-Howes. 2016. Effects of cyclone-generated disturbance on a tropical reef foraminifera assemblage. Scientific Reports 6:24846.

Strotz, L. C., E. E. Saupe, J. Kimmig, and B. S. Lieberman. 2018a. Metabolic rates, climate and macroevolution: a case study using Neogene molluscs. Proceedings of the Royal Society of London B 285:20181292.

Strotz, L. C., M. Simoes, M. G. Girard, L. Breitkreuz, J. Kimmig, and B. S. Lieberman. 2018b. Getting somewhere with the Red Queen: chasing a biologically modern definition of the hypothesis. Biology Letters 14:20170734.

Tilman, D. 1982. Resource competition and community structure. Princeton University Press, Princeton, N.J.
Topper, T. P., L. C. Strotz, L. E. Holmer, and J.-B. Caron. 2015. Survival on a soft seafloor: life strategies of brachiopods from the Cambrian Burgess Shale. Earth-Science Reviews 151:266-287.

Valentine, J. W. 1970. How many marine invertebrate fossil species? A new approximation. Journal of Paleontology 44:410-415.

Valentine, J. W., D. Jablonski, A. Z. Krug, and K. Roy. 2008. Incumbency, diversity, and latitudinal gradients. Paleobiology 34:169-178.

Villasenor, J. L., G. Ibarra-Manríquez, J. A. Meave, and E. Ortiz. 2005. Higher taxa as surrogates of plant biodiversity in a megadiverse country. Conservation Biology 19:232-238.

Vrba, E. S. 1985. Environment and evolution: alternative causes of the temporal distribution of evolutionary events. South African Journal of Science 81:229-236.

Vrba, E. S. 1992. Mammals as a key to evolutionary theory. Journal of Mammalogy 73:1-28.

Vrba, E. S. 1993. Turnover-pulses, the Red Queen, and related topics. American Journal of Science 293:418.

Whittaker, R. H. 1960. Vegetation of the Siskiyou Mountains, Oregon and California. Ecological Monographs 30:279-338.

Whittaker, R. J., K. J. Willis, and R. Field. 2001. Scale and species richness: towards a general, hierarchical theory of species diversity. Journal of Biogeography 28:453-470.

Wiley, E. O. 1978. The evolutionary species concept reconsidered. Systematic Zoology 27:17-26. 